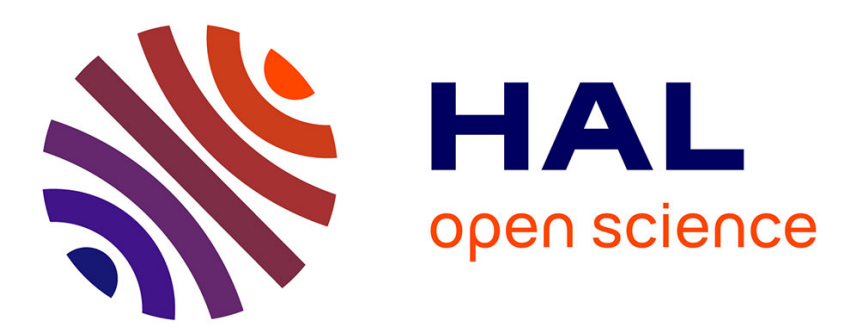

\title{
3D Simulation Analysis of Bipolar Amplification in Planar Double-Gate and FinFET with Independent Gates
}

Daniela Munteanu, Jean-Luc Autran, Mathieu Moreau

\section{- To cite this version:}

Daniela Munteanu, Jean-Luc Autran, Mathieu Moreau. 3D Simulation Analysis of Bipolar Amplification in Planar Double-Gate and FinFET with Independent Gates. Conference on Radiation Effects on Components and Systems (RADECS), Sep 2008, Jyväskylä, Finland. pp.280-283, 10.1109/RADECS.2008.5782727 . hal-01841105

\section{HAL Id: hal-01841105 \\ https://hal.science/hal-01841105}

Submitted on 17 Jul 2018

HAL is a multi-disciplinary open access archive for the deposit and dissemination of scientific research documents, whether they are published or not. The documents may come from teaching and research institutions in France or abroad, or from public or private research centers.
L'archive ouverte pluridisciplinaire HAL, est destinée au dépôt et à la diffusion de documents scientifiques de niveau recherche, publiés ou non, émanant des établissements d'enseignement et de recherche français ou étrangers, des laboratoires publics ou privés. 


\title{
3D Simulation Analysis of Bipolar Amplification in Planar Double-Gate and FinFET with Independent Gates
}

\author{
Daniela Munteanu, Jean-Luc Autran and Mathieu Moreau
}

\begin{abstract}
The bipolar amplification and charge collection of Planar Double-Gate and FinFET with independent gates is simulated. The transient response of independent gate devices is compared to that of conventional devices having the gates tied together.
\end{abstract}

Index Terms-Double-Gate, FinFET, independent gates, single event transient, heavy ion, charge collection, bipolar amplification

\section{INTRODUCTION}

$\mathrm{A}$ CMOS scaling is approaching its limits, Double-Gate (DG) MOSFET is recognized as the most scalable alternative to the conventional bulk MOSFET due to its high short-channel effects immunity [1]. In spite of excellent electrical performances due to its multiple conduction surfaces, conventional DG MOSFET allows only threeterminal (3T) operation because the two gate electrodes, i.e. the front gate and the back gate, are generally tied together. Planar Double-Gate and FinFET structures with independent gates have been recently proposed [2]-[4], allowing a four terminal (4T) operation. Independent-Gate Planar DoubleGate MOSFET (4T-DGFET) and FinFET (4T-FinFET) devices offer additional potentialities, such as a dynamic threshold voltage control by one of the two gates, transconductance modulation, signal mixer, in addition to the conventional switching operation. Thus, 4T-DGFET and 4TFinFET are promising for future high performance and low power consumption very large scale integrated circuits. Previous simulation studies demonstrate that 3T-DGFET and 3T-FinFET show better radiation hardness than Single-Gate fully-depleted SOI transistors [5]-[7], particularly due to the numerical simulation the sensitivity to single-event of

Manuscript received March 31, 2008. This work was supported by the MEDEA+ Project \#2A704 ROBIN and by the French Ministry of Research (ANR PNANO project "MULTIGRILLES").

D. Munteanu and M. Moreau are with IM2NP-CNRS, UMR CNRS 6242, Bât. IRPHE, 49 rue Joliot Curie, BP 146, 13384 Marseille Cedex 13, France (Phone: (33) $496139819 \quad$ - Fax: (33) 496139 709, Email: daniela.munteanu@univ-provence.fr).

J.L. Autran is with IM2NP-CNRS, UMR CNRS 6242, Bât. IRPHE, 49 rue Joliot Curie, BP 146, 13384 Marseille Cedex 13, France and with Institut Universitaire de France (IUF), 75000Paris, France (Email: jeanluc.autran@univ-provence.fr).
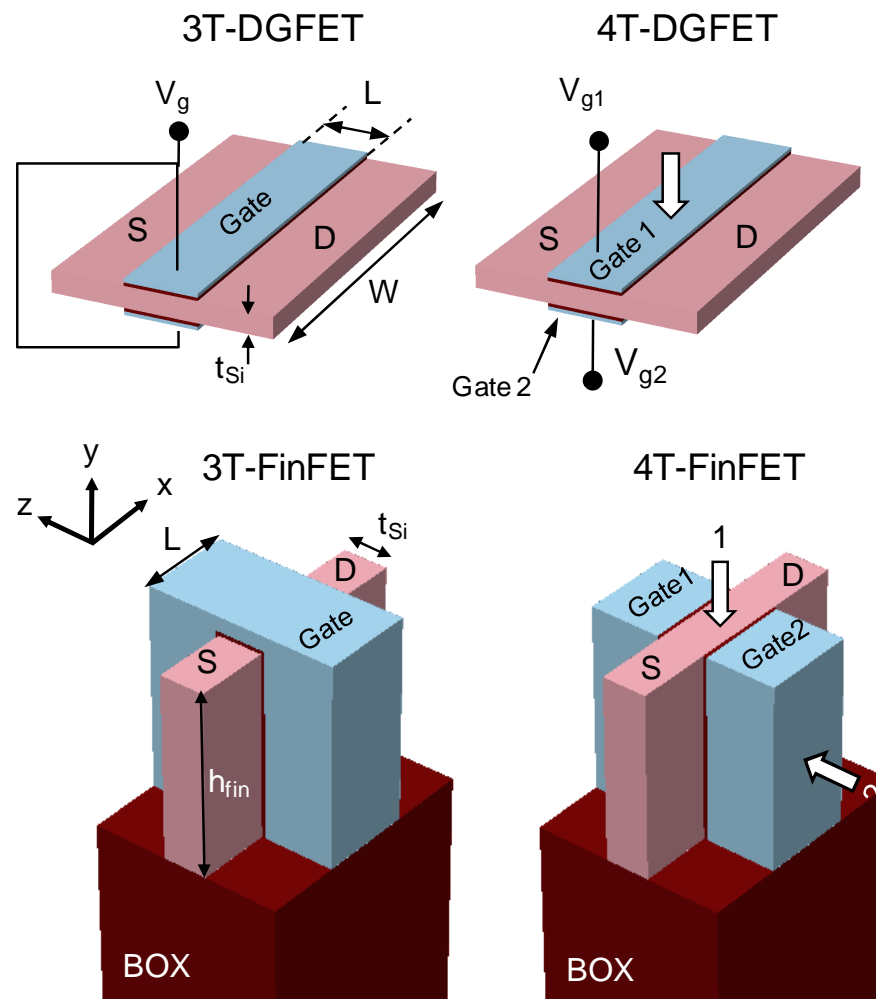

4T-FinFET
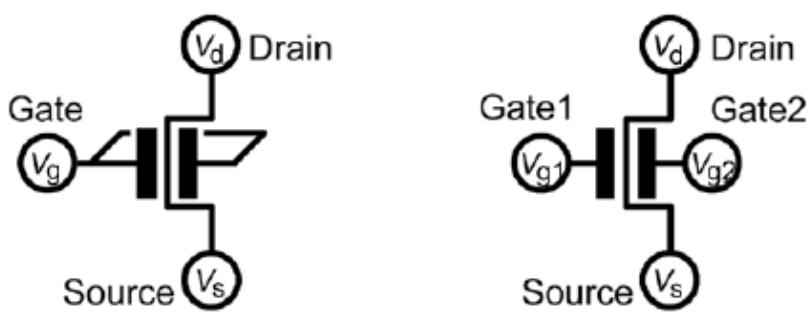

Fig. 1. Schematic description of the 3-D simulated DGFET and FinFET structures with three and four terminals considered in this work. The main geometrical parameters used in simulation are also defined. $(\mathrm{S}=$ source region and $\mathrm{D}=$ drain region)

enhanced control of the body potential and of the reduction of floating body effects. In the present work we investigate by 3D 4T-DGFET and 4T-FinFET devices compared with that of conventional 3T-DGFET and 3T-FinFET. The impact of the 
second gate bias on the transient response and bipolar amplification of the device submitted to heavy ion irradiation is particularly addressed.

\section{DESCRIPTION OF SIMULATED DEVICES AND SIMULATION DETAILS}

The description of the 3D architectures considered in the simulation and the definition of their geometrical parameters are represented in Fig. 1. Planar Double-Gate structures in both 3T-DGFET and 4T-DGFET configurations are based on that reported in [8]. For these devices the channel length is 20 $\mathrm{nm}$, the silicon film thickness is $6 \mathrm{~nm}$ and the gate oxide is 1 $\mathrm{nm}$-thick. An intrinsic channel and a gate width of $100 \mathrm{~nm}$ are also considered. In 3T-DGFET the two gates are tied together and are biased at $\mathrm{V}_{\mathrm{g}}$. In 4T-DGFET configuration the gates are biased independently at $\mathrm{V}_{\mathrm{g} 1}$ (front gate) and $\mathrm{V}_{\mathrm{g} 2}$ (back gate). FinFET structures are based on devices reported in [9]. An intrinsic fin-body with a $12 \mathrm{~nm}$-thick film thickness (or fin width, $\mathrm{t}_{\mathrm{Si}}$ ) and a device width $\mathrm{h}_{\mathrm{fin}}=50 \mathrm{~nm}$ (or fin height) are considered. The channel length is $25 \mathrm{~nm}$ and the front and back gate oxides are $1 \mathrm{~nm}$-thick.

3D numerical simulations have been performed with 3D Synopsis code [10], including the SRH and Auger recombination models and the Fermi-Dirac carrier statistics. Both the impact ionization and the carrier mobility depend on carrier energy calculated with the hydrodynamic model. The mobility model also includes the dependence on the lattice temperature and on the channel doping level.

The irradiation track has a Gaussian shape with narrow radius $(14 \mathrm{~nm})$ and a Gaussian time dependence, centered on $10 \mathrm{ps}$ and with a characteristic width of $2 \mathrm{ps}$. The ion strikes in the middle of the channel, as shown in Fig. 1. In planar DGFET, the ion strike is simulated in vertical incidence (parallel to the y axis). In FinFET, two ion strike directions have been considered: vertical (direction "1", parallel to the $y$ axis, Fig. 1) and horizontal (direction " 2 " parallel to the $\mathrm{z}$ axis and perpendicular to the gates, Fig. 1). The deposited charge is calculated considering the Gaussian distribution of the ion track and the 3D geometry of the silicon body. The collected charge is given by the drain current integration over the transient duration and the bipolar gain is finally calculated as the ratio between the collected and deposited charges.

\section{Planar DOUBle-GATE}

Figure 2 shows the static drain current characteristics as function of front gate bias in 4T-DGFET at different $\mathrm{V}_{\mathrm{g} 2}$ and in 3T-DGFET. As expected in 4T-DGFET, $\mathrm{V}_{\mathrm{g} 2}$ modulates the drain current and the main electrical parameters in the subthreshold regime (threshold voltage $\mathrm{V}_{\mathrm{T}}$, subthreshold swing $S$ and off-state current $I_{\text {off }}$ ).

The drain current transients produced by the ion strike are shown in Fig. 3a for a LET value of $1 \mathrm{MeV} /\left(\mathrm{mg} / \mathrm{cm}^{2}\right)$. The drain current peak in 4T-DGFET is higher than in 3T-DGFET for positive $\mathrm{V}_{\mathrm{g} 2}$ (and respectively lower for negative $\mathrm{V}_{\mathrm{g} 2}$ ), due to the higher $\mathrm{I}_{\mathrm{off}}$ current (and respectively lower $\mathrm{I}_{\mathrm{off}}$ current for negative $\mathrm{V}_{\mathrm{g} 2}$ ). However, the collected charge (Fig. 3b) is always higher in 4T-DGFET than in 3T-DGFET. In 4TDGFET, the control by the front of the electrostatic potential in the channel is less effective, which enhances the floating body effects and the collected charge and the parasitic bipolar amplification (Fig. 4) are higher.

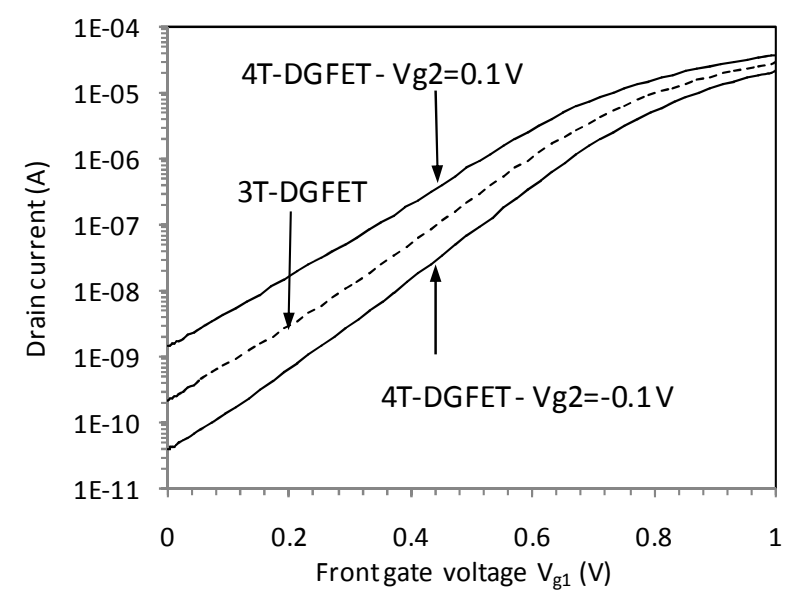

Fig. 2. Drain current characteristics as function of $\mathrm{V}_{\mathrm{g} 1}$ for 4T-DGFET with different back gate biases. The drain current versus $\mathrm{V}_{\mathrm{g}}$ of $3 \mathrm{~T}$-DGFET is also reported for comparison. $\mathrm{V}_{\mathrm{d}}=0.7 \mathrm{~V}$.
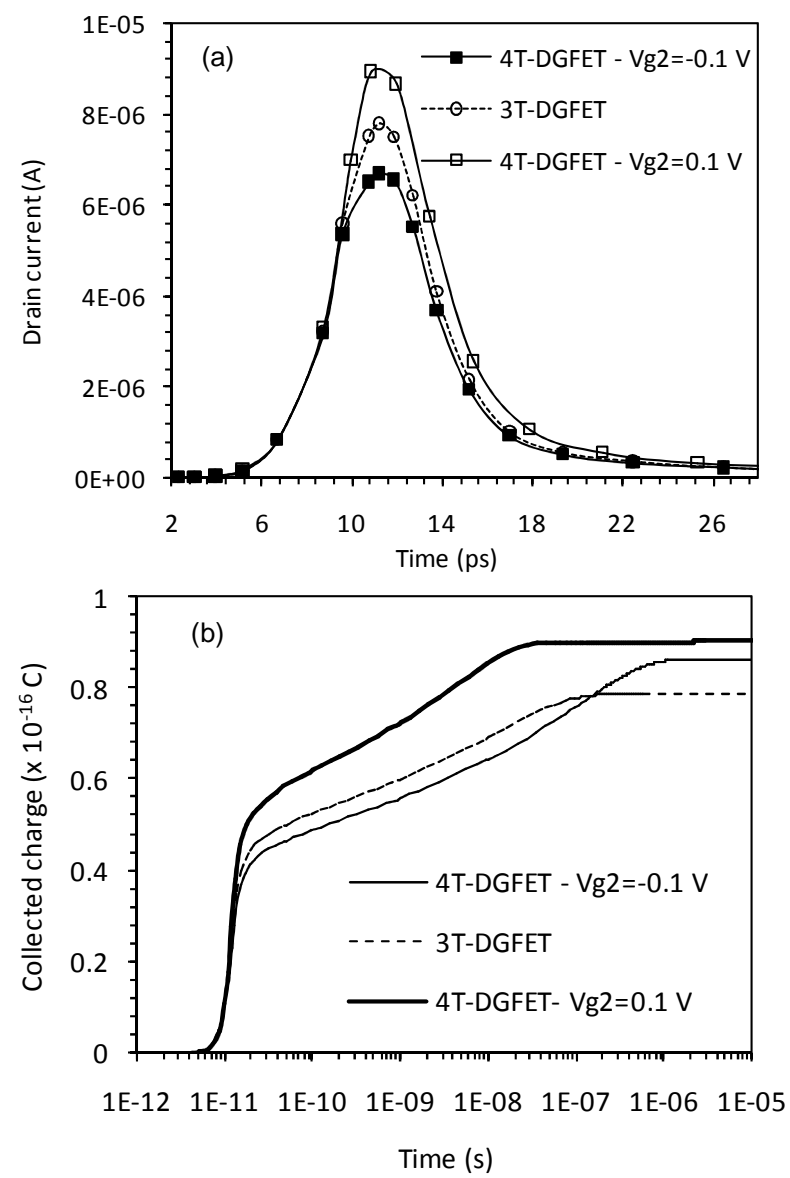

Fig. 3. Drain current transient (a) and collected charge (b) in 3T-DGFET and 4T-DGFET with $\mathrm{V}_{\mathrm{g} 2}=0.1 \mathrm{~V}$ and $\mathrm{V}_{\mathrm{g} 2}=-0.1 \mathrm{~V}$. The transistors are biased in offstate $\left(\mathrm{V}_{\mathrm{g}}=0 \mathrm{~V}\right.$ for 3T-DGFET and $\mathrm{V}_{\mathrm{g} 1}=0 \mathrm{~V}$ for 4T-DGFET) and $\mathrm{V}_{\mathrm{d}}=0.7 \mathrm{~V}$. The ion strike LET is $1 \mathrm{MeV} /\left(\mathrm{mg} / \mathrm{cm}^{2}\right)$. 


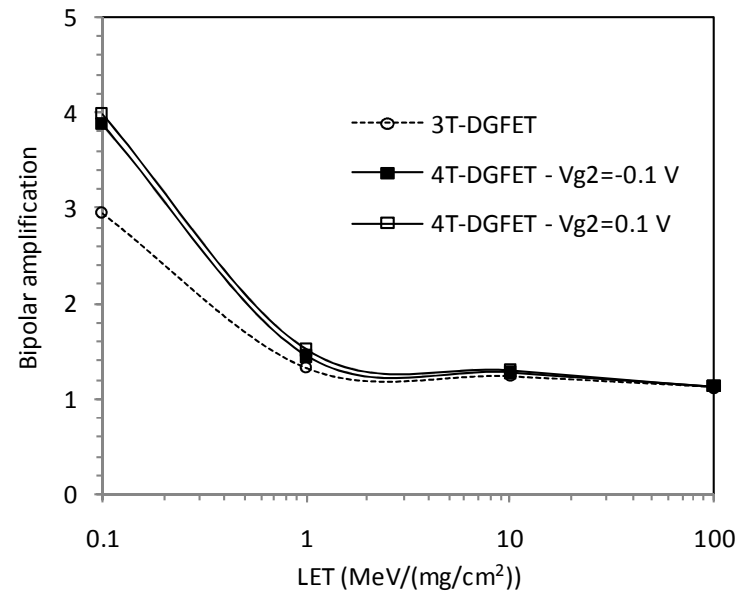

Fig. 4. Bipolar amplification as function of LET in 3T-DGFET and 4TDGFET at $\mathrm{V}_{\mathrm{g} 2}=0.1 \mathrm{~V}$ and $\mathrm{V}_{\mathrm{g} 2}=-0.1 \mathrm{~V}$.

\section{FinFET}

Static drain current characteristics as function of front gate bias in 4T-FinFET at different $\mathrm{V}_{\mathrm{g} 2}$ and in 3T-FinFET are shown in Fig. 5. In 3T-FinFET the gate better controls the potential in the silicon body and reduces short-channel effects. Then, $\mathrm{I}_{\text {off }}$ in 3T-FinFET is slightly lower than $\mathrm{I}_{\text {off }}$ in 4TFinFET with $\mathrm{V}_{\mathrm{g} 2}=0 \mathrm{~V}$ (Fig. 5) and the subthreshold slope is improved in 3T-FinFET compared to 4T-FinFET.

3D electron density profile in the silicon film of 3T-FinFET and 4T-FinFET at $\mathrm{V}_{\mathrm{g} 2}=-0.1 \mathrm{~V}$, before the ion strike, is presented in Fig. 6. In 4T-FinFET, near the back gate (gate 2) interface the electron density is lower than that of 3T-FinFET due to the negative bias of the back gate. $2 \mathrm{D}$ electron density in a vertical cross section perpendicular to the gates (C-C' cross-section shown in Fig. 6) confirms this observation.

Similar to Planar DGFET configuration, the peak of the drain current transient in 4T-FinFET is higher than in 3TFinFET for positive $\mathrm{V}_{\mathrm{g} 2}$ and smaller for negative $\mathrm{V}_{\mathrm{g} 2}$ (Fig. 8). The bipolar amplification (presented in Fig. 8 for an ion strike in vertical incidence) increases (at low LET) with the increase of positive $\mathrm{V}_{\mathrm{g} 2}$ and with the decrease of the negative $\mathrm{V}_{\mathrm{g} 2}$.

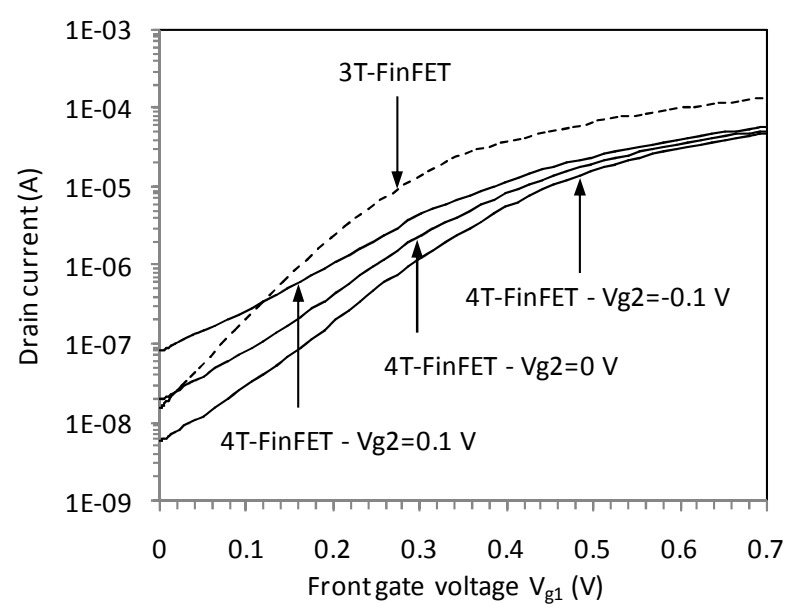

Fig. 5. Drain current characteristics as function of $V_{g 1}$ for 4T-DGFET at different back gate biases. The drain current curve versus $V_{g}$ in $3 T$-FinFET is also shown. $\mathrm{V}_{\mathrm{d}}=0.7 \mathrm{~V}$.

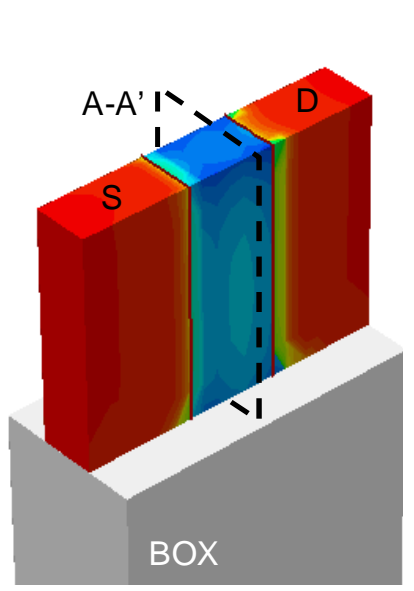

3T-FinFET

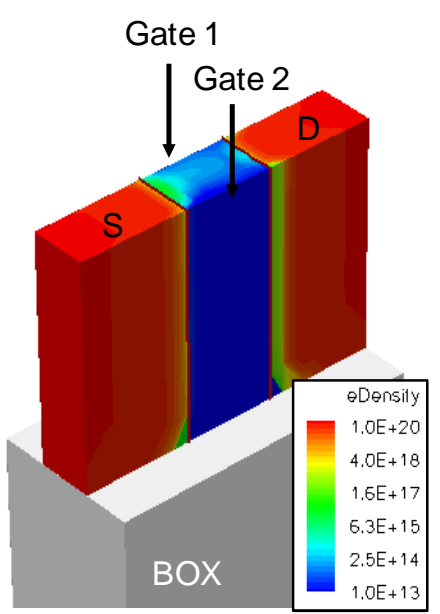

4T-FinFET
Fig. 6. 3D profile of electron density in the 3T- FinFET and 4T-FinFET at $\mathrm{V}_{\mathrm{g} 2}=-0.1 \mathrm{~V}$ before the ion strike. For a better view the gate material, oxide gate and spacers are not shown. $\mathrm{V}_{\mathrm{g}}=0 \mathrm{~V}$ for 3T-FinFET and $\mathrm{V}_{\mathrm{g} 1}=0 \mathrm{~V}$ for $4 \mathrm{~T}$ FinFET. $\mathrm{V}_{\mathrm{d}}=0.7 \mathrm{~V}$.

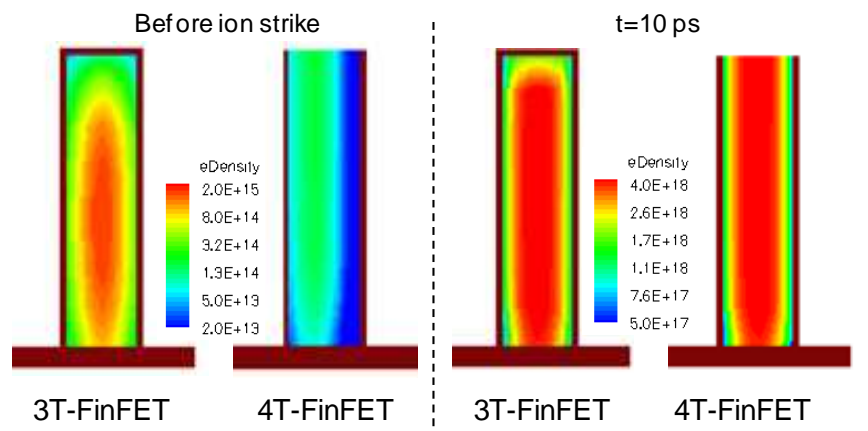

Fig. 7. 2D profile of electron density in a vertical cross-section (A-A' plane defined in Fig. 6) in the middle of the channel of 3D FinFET before the ion strike and at $\mathrm{t}=10 \mathrm{ps}$ (maximum charge generation). The gate material and a part of the buried oxide are not shown. $\mathrm{V}_{\mathrm{g}}=0 \mathrm{~V}$ for 3T-FinFET. $\mathrm{V}_{\mathrm{g} 1}=0 \mathrm{~V}$ and $\mathrm{V}_{\mathrm{g} 2}=-0.1 \mathrm{~V}$ for 4T-FinFET. $\mathrm{V}_{\mathrm{d}}=0.7 \mathrm{~V}$. The ion strike LET is 1 $\mathrm{MeV} /\left(\mathrm{mg} / \mathrm{cm}^{2}\right)$.

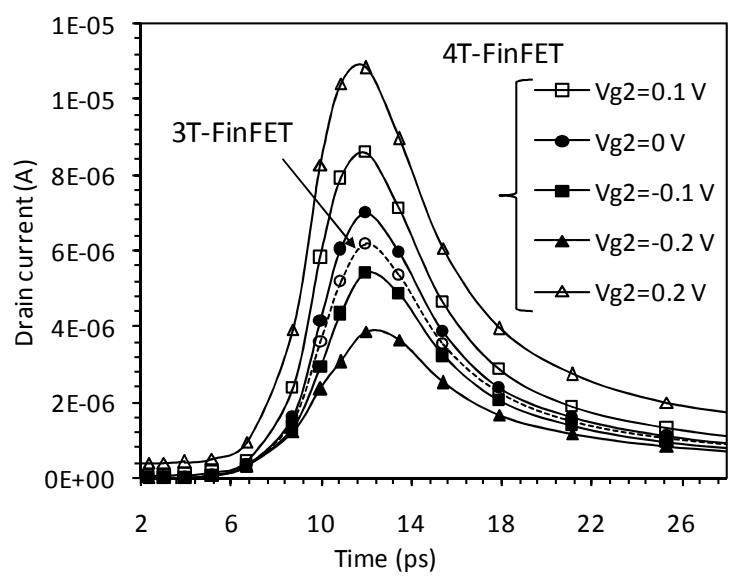

Fig. 8. Drain current transients in 3T-FinFET and 4T-FinFET (at different back gate biases) for an ion strike in vertical incidence. The transistors are biased in off-state $\left(\mathrm{V}_{\mathrm{g}}=0 \mathrm{~V}\right.$ for 3T-FinFET and $\mathrm{V}_{\mathrm{g} 1}=0 \mathrm{~V}$ for 4T-FinFET) and $\mathrm{V}_{\mathrm{d}}=0.7 \mathrm{~V}$. The ion strike LET is $0.1 \mathrm{MeV} /\left(\mathrm{mg} / \mathrm{cm}^{2}\right)$. 


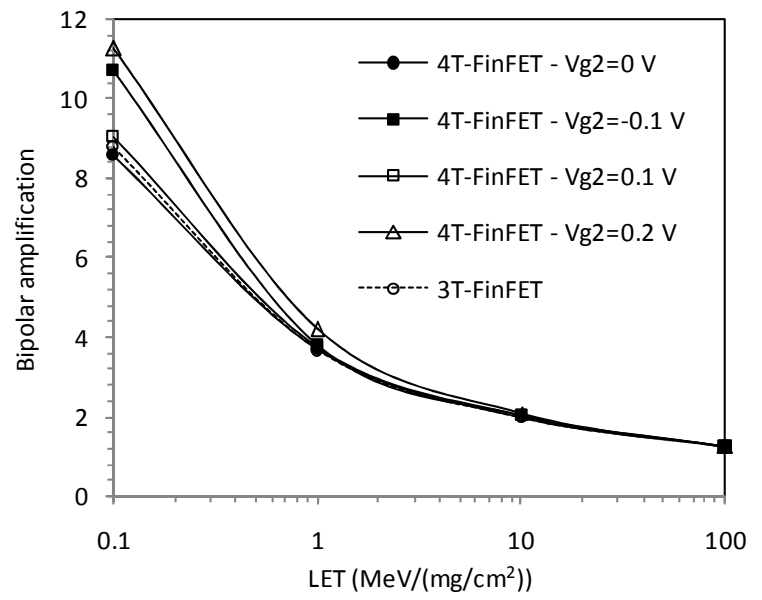

Fig. 9. Bipolar amplification versus LET in 3T-FinFET and 4T-FinFET (at different back gate biases) for an ion strike in vertical incidence. The transistors are biased in off-state $\left(\mathrm{V}_{\mathrm{g}}=0 \mathrm{~V}\right.$ for 3T-DGFET and $\mathrm{V}_{\mathrm{g} 1}=0 \mathrm{~V}$ for 4T-DGFET) and $\mathrm{V}_{\mathrm{d}}=0.7 \mathrm{~V}$.

\section{DISCUSSION}

To facilitate the comparison between FinFET and Planar DGFET, we simulate the transient response for an ion striking horizontally, parallel to the z-axis (perpendicular to the gates, direction "2") in 4T-FinFET. Figure 10 compares drain current transients in 4T-FinFET for the two ion strike directions. The simulation results show that the peak of the drain current transient is lower for a horizontal ion strike than for a vertical ion strike. The collected charge is smaller for an ion striking horizontally on the gates of 4T-FinFET than for a vertical strike, because of a lower deposited charge. However, the bipolar amplification is higher at low LET for a horizontal strike than for a vertical strike, as shown in Fig. 11.

Finally, the bipolar gain is found to be higher in 4T-FinFET than in 4T-DGFET for all LET values. This is due to the thicker silicon film considered in FinFET architectures (12 nm compared to $6 \mathrm{~nm}$ in DGFET). Then, floating body effects are more important in FinFET (because the front gate control over the body potential is less effective), which leads to more important bipolar amplification.

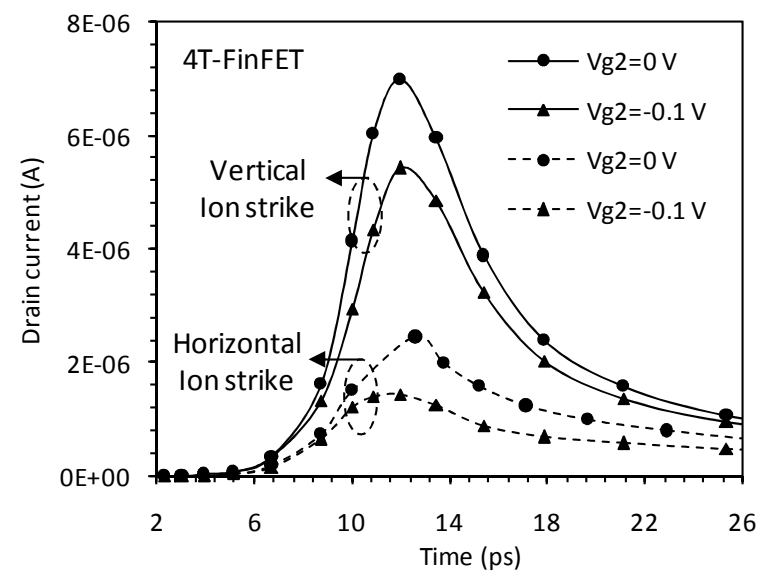

Fig. 10. Drain current transients in 4T-DGFET for vertical and horizontal ion strikes. The ion strike LET is $0.1 \mathrm{MeV} /\left(\mathrm{mg} / \mathrm{cm}^{2}\right)$.

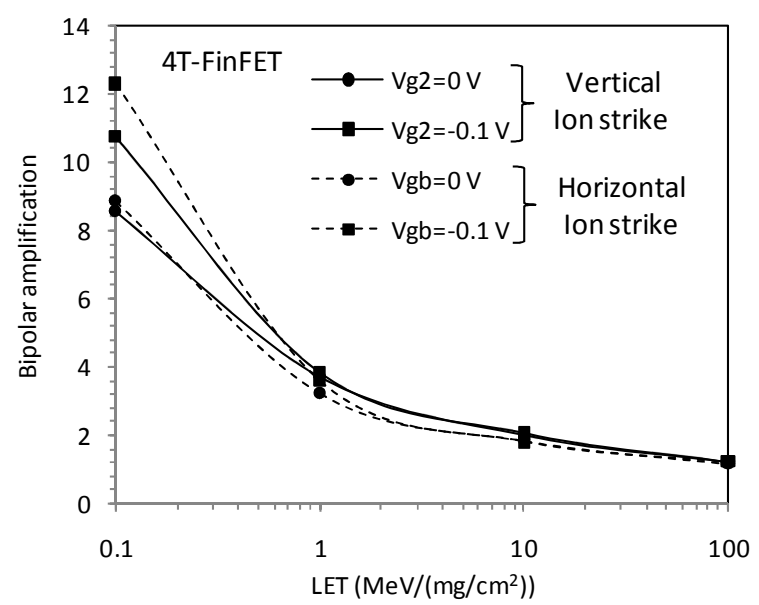

Fig. 11. Bipolar amplification versus LET in 4T-DGFET for vertical and horizontal ion strikes.

\section{CONCLUSION}

This paper presents the transient response to heavy ion irradiation of independent gate (4 terminals) DGFET and FinFET. The bipolar gain and charge collection of 4T-DGFET and 4T-FinFET are analyzed as function of LET and ion strike location, and compared to that of 3T-DGET and 3T-FinFET, respectively. Our results show that the bipolar amplification is higher in independent-gates devices for both positive and negative back gate bias. The bipolar gain of FinFET is found to be higher than the bipolar amplification of DGFET, due to the thicker silicon body considered for the first architecture.

\section{REFERENCES}

[1] W. Haensch, E. J. Nowak, R. H. Dennard, P. M. Solomon, A. Bryant, O.H. Dokumaci, A. Kumar, X. Wang, J. B. Johnson, M. V. Fischetti, "Silicon CMOS devices beyond scaling", IBM J. Res Develop., vol. 50, no. 4/5, pp. 339-361, 2006.

[2] M. Masahara, Y. Liu, K. Sakamoto, K. Endo, T. Matsukawa, K. Ishii, T. Sekigawa, H. Yamauchi et al., "Demonstration, Analysis, and Device Design Considerations for Independent DG MOSFETs", IEEE Trans. Electron. Dev. 52, pp. 2046-2051, 2005

[3] G. Pei and E.C. Kan, "Independently Driven DG MOSFETs for MixedSignal Circuits: Part I-Quasi-Static and Nonquasi-Static Channel Coupling", IEEE Trans. Electron. Dev. 51, 2086-2093, 2004.

[4] L. Mathew, Y. Du, A.V. Thean, M. Sadd, A. Vandooren, C. Parker, et al., "CMOS vertical Multiple Independent Gate Field Effect Transistor (MIGFET)”, in Proc. IEEE Int. SOI Conf., Oct. 2004, pp. 187-189.

[5] K. Castellani, D. Munteanu, J.L. Autran, V. Ferlet-Cavrois, P. Paillet, J. Baggio, "Simulation Analysis of the Bipolar Amplification Induced by Heavy-Ion Irradiation in Double-Gate MOSFETs", IEEE Trans. Nucl. Sci., vol. 52, no. 6, pp. 2137-2143, Dec. 2005.

[6] D. Munteanu, V. Ferlet-Cavrois, J.L. Autran, P. Paillet, J. Baggio, O. Faynot, C. Jahan, L. Tosti, "Investigation of Quantum Effects in UltraThin Body Single- and Double-Gate Devices Submitted to Heavy Ion Irradiation", IEEE Trans. Nucl. Sci., vol. 53, no. 6, pp. 3363, 2006.

[7] D. Munteanu, J. L. Autran, V. Ferlet-Cavrois, P. Paillet, J. Baggio, K. Castellani, "3-D Quantum Numerical Simulation of Single-Event Transients in Multiple-Gate Nanowire MOSFETs", IEEE Trans. Nucl. Sci., vol. 54, no. 4, pp. 994-1001, Aug. 2007.

[8] M. Vinet, T. Poiroux, J. Widiez, J. Lolivier, B. Previtali, C. Vizioz, et al., "Bonded Planar Double-Metal-Gate NMOS Transistors Down to 10 nm”, IEEE Electron Dev. Lett., vol. 26, no. 5, pp. 317-319, May 2005.

[9] Z. Lu and J. G. Fossum, "Short-channel effects in Independent-Gate FinFETs" IEEE Electron Dev. Lett., vol. 28, no. 2, pp. 145, Feb. 2007.

[10] Synopsys Sentaurus TCAD tools, Available online: http://www.synopsys.com/products/tcad/tcad.html. 